\title{
Central Park y la producción del espacio público: el uso de la ciudad y la regulación del comportamiento urbano en la historia
}

Álvaro Sevilla-Buitrago. Universidad Politécnica de Madrid, Madrid, España.

RESUMeN | Los debates contemporáneos sobre el eclipse del espacio público suelen ofrecer una visión idealizada de su pasado, impidiendo una correcta reconsideración del papel que las técnicas urbanísticas han tenido en la producción y evolución del mismo. Contribuyendo al desarrollo de una historia crítica que subsane estas lagunas, Central Park se presenta aquí como un dispositivo gubernamental ideado para sustituir el régimen de uso del espacio público habitual en las calles de Manhattan a mediados del siglo XIX, por un nuevo conjunto de prácticas espaciales definidas y monitorizadas por el Estado. Tras una descripción de las formas de apropiación espontánea de la calle por parte de las clases populares, se analizan los distintos niveles proyectuales en los cuales se articulaba esta estrategia de domesticación del espacio público: del propio diseño espacial y concepción de la red de lugares del parque, a la regulación normativa del uso y comportamiento de los visitantes, al ejercicio activo de vigilancia y castigo de conductas y sujetos indeseables.

PaLABras Clave | espacio público, conflicto social, historia urbana.

ABSTRACT | Contemporary debates on the eclipse of public space usually provide an idealized interpretation of its past, avoiding a proper consideration of the role that planning techniques have played in the evolution of this phenomenon. Contributing to the development of a critical history that helps correct such knowledge gaps, this article presents New York's Central Park as a governmental device aimed at replacing the regime for the use of public space developed during the mid-nineteenth century regarding the streets of Manhattan, with a new set of spatial practices that are defined and monitored by the State. The article begins with a description of the spontaneous appropriation of the streets during this period and the resulting contradictions that occurred. This is followed by an analysis of the different levels of articulation between such behavior and the park's strategy of domestication, from the design of the network of places, to the normative regulation of the visitors' behavior and use of space, to the active surveillance and punishment of unde-sired behaviors and subjects.

KEY WORDs | public space, social conflict, urban history.

Recibido el 8 de enero de 2013, aprobado el 18 de julio de 2013

E-mail: alvaro.sevilla@upm.es 


\section{Introducción: las técnicas urbanísticas en el eclipse del espacio público}

En una de las lecturas del espacio público urbano más influyentes de las últimas décadas, Don Mitchell (1995) sugería que su contenido y significado son el fruto inestable de una dialéctica socioespacial más amplia: la pugna entre los usos del espacio y la concepción del mismo, entre el espacio vivido-apropiado y el espacio planificado-regulado, entre los espacios representacionales y las representaciones del espacio. Es esta oposición la que, según Mitchell, conforma los contornos políticos del espacio público y su rol como índice del carácter democrático de una sociedad. Ningún proyecto o práctica puede agotar esa dialéctica, señala: el espacio público es siempre "el producto de ideas enfrentadas acerca de lo que constituye ese espacio (...) y quién forma parte del "público"' (p. 115). Esta contribución supuso una intervención polémica frente a los trabajos que, en años anteriores, habían generalizado la idea del eclipse del espacio público en la ciudad contemporánea bajo el dictado de nuevos entramados político-económicos (Sennett, 1992; Sorkin, 1992). Desde entonces, son numerosas las aportaciones que han destacado la irreducible apertura ontológica y política del espacio público y la incapacidad de los proyectos institucionales para "cercarlo", para monopolizar su significado y monitorizar exhaustivamente las prácticas que en él se despliegan (véase, por ejemplo, Butler, 2011; Dikeç, 2005; Massey, 2005; Rancière, 2003; Žižek, 2012).

Pero a pesar de su interés por comprender las prácticas sociales en el espacio público y su articulación a momentos políticos más amplios, este debate presta una atención menor a los mecanismos y técnicas a través de los cuales el urbanismo ha intentado mediar históricamente en esas dinámicas. Con frecuencia, de hecho, esa perspectiva aparece deformada por una visión idealizada de regímenes de espacio público pretéritos. En ese sentido, debemos cuestionar más detenidamente el rol histórico de las políticas urbanas en la producción de dichos regímenes. ¿Qué papel ha desempeńado la planificación en su evolución? ¿De qué forma incentiva u obstaculiza las estrategias institucionales y las tácticas de apropiación espontánea del espacio? ¿Es la pobreza actual del espacio público fruto de tendencias económicopolíticas históricamente específicas, respecto de las cuales el urbanismo llevaría a cabo una misión subordinada y ejecutiva? ¿Es, por el contrario, consecuencia de una forma de producción del espacio desencadenada precisamente por los métodos implícitos en planes y proyectos urbanos? La capacidad de responder a estas preguntas y de comprometer nuestra disciplina en un esfuerzo por crear espacios públicos vitales, justos y democráticos depende, entre otras cosas, del modo en que interroguemos el presente y el pasado de nuestras técnicas. Esto exige una actitud crítica que debe extenderse a aquellos episodios que la historiografía convencional ha considerado conspicuos, con el fin de averiguar, en su caso, cómo han imaginado esos urbanismos el cierre del horizonte del espacio público. Se trata de un proyecto de revisión profunda que debería definirse en términos fundamentalmente operativos, como una historia del presente de nuestras prácticas urbanas y urbanísticas: una historia de cómo los usos actuales del espacio público han llegado a ser posibles; una historia de las instancias sociopolíticas que anidan silenciosamente 
en nuestras técnicas (De Certeau, 1988, p. 94; Elden, Gregory \& Sevilla-Buitrago, 2011; Foucault, 1975, p. 35).

Este artículo estudia un episodio importante de esa historia: la propuesta de Central Park como un antídoto al régimen de espacio público habitual en las calles de Nueva York a mediados del siglo xIx. El análisis se centra en el proceso de concepción y primeros pasos del proyecto, una encrucijada clave en la historia del urbanismo. El discurso y prácticas inaugurados en esta iniciativa ejercerán una extraordinaria influencia no sólo en las políticas de parques de otras grandes ciudades estadounidenses en las décadas siguientes (Cranz, 1982), sino más ampliamente en la larga tradición que ve institucionalizarse la planificación entre la Progressive Era (Boyer, 1992) y los intrépidos años del New Deal (Stein, 1957). La figura de Frederick Law Olmsted -responsable del proyecto junto al arquitecto Calvert Vaux, Superintendente y Arquitecto-Jefe del parque- y su experiencia en Central Park, han seguido representando un punto de referencia constante no sólo para la historiografía posterior y para la imagen que la disciplina ha construido de sí misma por medio de ella, sino también para las propias políticas locales en Nueva York; entre otras, la propia rehabilitación del parque a partir de la década de 1980.

Con todo, Central Park sigue siendo un territorio abierto. El proyecto inicial ha recibido amplia atención académica, con perspectivas que van desde la caracterización convencional como una medida reformista encaminada a proporcionar espacios libres saludables en respuesta a los crecientes conflictos de la industrialización (Cranz, 1982), a la descripción del parque como un emplazamiento para el disfrute exclusivo y conspicuo de la burguesía local (Rosenzweig \& Blackmar, 1992); o desde el aumento de las rentas del suelo en el por entonces casi vacío uptown (Gandy, 2002), al análisis crítico pero funcionalista del proyecto como un dispositivo de control y vigilancia de las clases trabajadoras (Taylor, 1999). A pesar de la erudición y riqueza de sus planteamientos, estas aportaciones describen sólo una parte de la verdad sobre Central Park. Tomadas aisladamente, dibujan una imagen demasiado parcial de los verdaderos objetivos de la iniciativa y, sobre todo, una descripción pobre de su rol en la política urbanística local o de sus lecciones para nuestras prácticas presentes. Ni equipamiento exclusivo para el capricho y beneficio económico de las élites, ni herramienta para la represión de las clases populares. Según sus promotores, Central Park debía ser, más bien, el desencadenante de un nuevo régimen de uso del espacio público en la ciudad, capaz de corregir las contradicciones que hacían de las calles de Manhattan un territorio ingobernable. El nuevo orden socioespacial prefigurado e inaugurado por el parque público suprimiría las prácticas que refutaban la incipiente espacialidad burguesa de la época (Domosh, 1998), permitiendo a las élites y las clases populares coexistir bajo un código de conducta regulado y ordenado, previsible y libre de conflictos. Para ello, en todo caso, sería necesario llevar a cabo un ejercicio profundo de reeducación de los modos de uso del espacio típicos en las clases trabajadoras. Estas formas de apropiación del espacio público -habituales en la mayor parte de la ciudad en el momento de creación de Central Park- habían permitido a los más humildes subsistir, en un contexto de creciente precarización del trabajo y la vida cotidiana, mediante el uso de la ciudad y sus calles como un recurso básico, como 
un "común” informal. La eventual proliferación de las prácticas espaciales inducidas por el parque habría provocado la desaparición de estas espacialidades y, con ellas, la de modos de reproducción social y capitales sociales autónomos, fundamentales no sólo para la supervivencia de los trabajadores más pobres, sino también para el propio auge económico de la ciudad durante este período.

Como otros grandes esquemas, Central Park fracasaría parcialmente en este intento. Los profundos cambios sociales que Olmsted y los miembros del Board of Commissioners of the Central Park (всср / Junta de Comisionados del Central Park), que gestionaba el parque, habían prometido tardarían en materializarse y lo harían sólo en combinación con otras políticas urbanas y sociales más directas. Sin embargo su herencia ideológica y metodológica nutriría la imaginación y procedimientos de los urbanistas de generaciones posteriores. El modus operandi abierto de forma experimental por Central Park, su vocación de monitorizar los regímenes de espacio público, llegarían a hacerse hegemónicos en décadas posteriores, prolongando así un ejercicio inadvertido de desposesión, implícito en la lógica profunda de las técnicas y modelos urbanos subsiguientes.

\section{Desgobierno y autonomía en la república de las calles}

Nueva York inauguró su pugna comercial con otras ciudades de la Costa Este durante la Guerra de Independencia y tomó el liderazgo en el comercio portuario al iniciarse el segundo cuarto del siglo xIx, gracias al desarrollo de nuevas infraestructuras territoriales que hacían de la ciudad una charnela entre la región interior de los Great Lakes y el tráfico en el Atlántico. Los cambios demográficos no se harían esperar: entre 1790 y 1860, Manhattan pasó de tener poco más de 30.000 habitantes a superar los 800.000. La revolución de la economía local y el reescalamiento de sus redes comerciales y laborales desencadenarían grandes turbulencias en estas décadas, que unían al desequilibrio económico una creciente conflictividad social expresada en revueltas periódicas y una emergente organización de la clase trabajadora (Bernstein, 1990). La industrialización metropolitana que la ciudad venía experimentando desde finales del siglo XviII se intensificó especialmente a partir de la década de $1820^{1}$. La explosión de la economía local, los cambios en los modos y relaciones de producción, en las formas de distribución y comercio, tuvieron un impacto profundo en la estructura social y, especialmente, en los modos de reproducción de la fuerza de trabajo.

Estas transformaciones provocarían, por supuesto, una reconfiguración a largo plazo en la estructura y el tejido urbanos, desencadenando diversos procesos de diferenciación espacial que se intensificarían progresivamente en las décadas siguientes: la especialización funcional de la ciudad, la expulsión paulatina de actividades incompatibles o poco lucrativas a las periferias y umbrales periurbanos, la aparición de nuevos modelos de alojamiento, la segregación residencial de la población por clase, etnia y raza, etcétera (Scherzer, 1992). Pero mientras estas dinámicas profundas rehacían el cuerpo de la ciudad, otras alteraciones, mucho más rápidas y obvias, estaban

Sobre el concepto de "industrialización metropolitana”, véase Wilentz (2004, pp. 107-142). 
desdibujando su rostro más evidente: los usos y significados del espacio público. Los cambios económicos y sociales de la ciudad estaban impulsando una profunda transformación de los patrones de vida cotidiana y uso de la ciudad, un nuevo universo callejero que la burguesía percibía como un deterioro del orden tradicional causado por la ausencia de una regulación efectiva. Se rastrearán a continuación las causas de estas alteraciones en relación con tres de las dinámicas de cambio más amplias y fundamentales en la época: i) las transformaciones en la esfera de la producción con la extinción de la vieja manufactura artesanal local y la emergencia de una rudimentaria industria de producción en masa; ii) los cambios en la esfera de la distribución y la reestructuración del comercio minorista; iii) la reorganización social del consumo conspicuo de las élites.

La expansión del mercado produjo un proceso de segmentación y especialización de la oferta con el que buena parte de los viejos maestros artesanos abandonó los esquemas productivos tradicionales. La demanda ampliada de productos de menor calidad les permitió sustituir a los aprendices y oficiales por trabajadores asalariados menos cualificados. Junto al aumento del volumen total de actividad, este cambio en la composición de la demanda de trabajo alimentó el "efecto llamada" a nuevas oleadas de inmigrantes que huían de una Europa envuelta en conflictos bélicos, revueltas sociales y agudos períodos de escasez y hambre, de forma especialmente intensa en la década de 1840 (Bernstein, 1990, p. 79; Wilentz, 2004, pp. 107-142). La precariedad de las nuevas relaciones de producción, los frecuentes períodos de recesión y recuperación y la incapacidad de la ciudad para asimilar estos rápidos cambios tuvieron una repercusión directa sobre las calles de Manhattan. El aumento de masas de trabajadores pobres llegadas del Viejo Mundo ${ }^{2}$, especialmente desde áreas rurales, trajo consigo formas de vida cotidiana y de uso del espacio público contrarias a las que la élite deseaba. El hacinamiento y el aumento de actividad en los barrios populares empujaban a los recién llegados a la calle, donde dichos patrones eran desplegados con toda su carga antagonista (Blackmar, 1989; Plunz, 1990). El creciente número de personas sin techo expulsadas de los circuitos de trabajo formal contribuía a intensificar aún más esta dinámica. Los cambios en las formas de empleo y los nuevos esquemas de trabajo a domicilio reestructuraron la unidad familiar, la organización de la economía doméstica y la rutina diaria. Los niños no podían ya incorporarse como aprendices a un artesanado en vías de extinción y las mujeres se veían obligadas a completar los ingresos familiares o cubrir la ausencia de ingresos masculinos con trabajos complementarios o recurriendo a la comunidad en busca de ayuda (Stansell, 1987).

A la intensificación de la actividad callejera por los cambios en la esfera productiva se sumaban los derivados de la reestructuración del comercio minorista local. El sistema tradicional de mercados públicos fue debilitándose paulatinamente hasta culminar en la desregulación total de la actividad comercial a comienzos de la década de 1840 (Burrows \& Wallace, 2000, p. 739). Las otrora sólidas organizaciones de comerciantes se vieron superadas por los vendedores ambulantes, las pequeńas tiendas de la esquina -que habitualmente mezclaban la venta de alimentos

Hacia mediados de siglo, tres cuartas partes de los trabajadores eran inmigrantes (Stott, 1990, p. 84). 
de primera necesidad con otros productos y el despacho de bebidas- o, incluso, por la venta desde los hogares. A esta diseminación de la actividad comercial siguieron otras realidades y, de entre los intersticios de esa crepitante esfera pública, floreció un nuevo paisaje informal poblado por traperos, mercachifles, vagabundos, niños dedicados al pillaje y la recogida de desechos, cartoneros y prostitutas.

Esta escena urbana entraba en contradicción directa con la formación de nuevas pautas de consumo conspicuo y de una nueva espacialidad femenina asociada a ellas (Boyer, 1985, pp. 43-129). La expansión económica impulsó una diversificación de la oferta en los segmentos medio y alto del mercado que reclamaba una demanda apropiada. Esta presión sistémica alteró el tradicional modelo de espacio social asociado al principio de las "esferas separadas". Según esta, la actividad productiva, la vida política y la presencia en el espacio público eran prerrogativas masculinas, mientras la mujer quedaba ligada al ámbito doméstico y la esfera del cuidado y la reproducción social. Las actividades relacionadas con el consumo estaban entre las pocas oportunidades que las mujeres tenían de salir del hogar y la creciente influencia de los nuevos mercados en formación ampliaría esta brecha ostensiblemente (Bondi \& Domosh, 1998, pp. 270, 280). Pero a pesar de la proliferación de nuevos espacios de consumo "feminizados" - los suntuosos centros comerciales de Stewart o McCreery y los establecimientos en Ladies Mile-, las calles eran aún un territorio compartido por ricos y pobres; las mujeres de clase media y alta que se aventuraban a una tarde de compras debían enfrentarse al espectáculo indecoroso que las clases populares desplegaban en ellas (Beckert, 2003, pp. 47-48). En definitiva, los cuadros morales y los cuadros materiales de la hegemonía burguesa estaban entrando en conflicto en el espacio público.

Las tensiones no pararían de intensificarse con la expansión económica de la ciudad. La nueva generación de clases adineradas ligada a la expansión financiera de mediados de siglo demandaba un lugar propio en la isla, un espacio público en el que pudieran reconocerse como grupo social y equipararse a las burguesías europeas. Éstas habían encontrado en las operaciones de renovación urbana coetáneas una oportunidad para producir un nuevo capital simbólico, pero la élite neoyorquina carecía de enclaves similares en la que, aún bien entrado el siglo, seguía considerándose "la ciudad más sucia de la Unión", hecha de calles estrechas, pestilentes, llenas de barro y ruido (Bellows, 1861; Greene, 1837, p. 170). ¿Cómo funcionaba esta "república de las calles"? El contenido urbano de la ciudad se componía de una densa superposición de estratos, incluyendo desde usos simples como el transporte, el paseo o el acceso a inmuebles y establecimientos, a otros menos evidentes pero con una notable presencia física y simbólica. Esta acumulación de códigos y significados se producía en un régimen de informalidad del que no escapaban ni las áreas más elegantes. Incluso los flamantes grandes almacenes de A.T. Stewart, abiertos en 1846 , se veían rodeados de buhoneros y quincalleros, muchos de ellos niños (Stansell, 1982, p. 313). A pesar de las tendencias a la especialización desencadenadas en algunas zonas tras el Gran Incendio de 1835, hacia mediados de siglo la mezcla de actividades en las áreas centrales de la ciudad se mantenía casi intacta. Esa mezcla de usos y funciones acarreaba también una mixtura social. El comentarista Edward W. Martin indicaba que, en Manhattan, "lo alto y lo bajo, ricos y pobres, pasan por estas aceras (...). Caballeros elegantes embutidos en velarte, damas cubiertas de seda 
y joyas, y escuálidos vagabundos vestidos con andrajos, se unen aquí en una verdadera confusión republicana” (citado en Domosh, 1998, p. 215). Con la inmigración aumentaba el número de vagabundos, mendigos y miembros de bandas callejeras, y con éstos, el sensacionalismo de la prensa local, que inundaba cada día con crónicas frescas sobre los últimos ultrajes en la que algunos tabloides consideraban la capital del crimen americano. Así, hacia el inicio de la segunda mitad del siglo se extendió una creciente alarma sobre la situación del espacio público, que conduciría a la "emergencia de la vida de la calle como un objetivo de la reforma organizada" (Stansell, 1982, p. 323).

La organización del espacio en los barrios populares era el mayor reto para ese nuevo proyecto. La propia imagen del "hogar" como espacio privado, protegido del exterior, que el movimiento reformista pretendía emplear para la correcta formación de los individuos, era refutada en estos enclaves. Aquí la divisoria entre lo público y lo privado era muy tenue, "las nociones de privacidad doméstica parecían ausentes, la gente circulaba continuamente entre las calles, sus propios hogares y los de otros" (Stansell, 1987, p. 42). Los barrios de clase alta se desprenderían pronto de cualquier actividad no residencial, pero las limitaciones de tiempo y el coste del transporte colectivo obligaban a los trabajadores a vivir cerca de sus puestos de trabajo. En sus espacios cotidianos se mezclaban las actividades de producción y reproducción de la fuerza de trabajo. Los jornaleros llegaron a comprender estos enclaves como "lugares específicamente obreros" y "el barrio y sus instituciones como su propio entorno social” (Bernstein, 1990, p. 105). Aunque por supuesto los barrios estaban repletos de disputas y rencillas, también servían a los trabajadores como un recurso básico, tanto en momentos difíciles -los taberneros y dueños de tiendas solían prestar dinero a las familias en apuros y apoyar a sus parroquianos a organizar revueltas o salir adelante durante las huelgas (Stelzle, 1926, p. 48)- como en el día a día. Las redes étnicas introducían a los recién llegados a la ciudad en comunidades ya maduras -aunque salvajemente enfrentadas a grupos vecinos-, las asociaciones de clan y vecinales organizaban el mercado de trabajo para resistir la presión en la fábrica y el taller -aunque también para expulsar a los ajenos a la comunidad-, los salones y tabernas servían para intercambiar información valiosa o cerrar pactos políticos -y también, desde luego, para celebrar, beber y jugar (Burrows \& Wallace, 2000, p. 754)-. Las mujeres hacían un uso muy intenso de los recursos del barrio mediante redes de amistad que "entretejían el hogar con el mundo de las calles" y "generaban un intrincado entramado de trueque e intercambio entre vecinas" (Stansell, 1987, p. 49). En casa, la calle estaba por todos sitios y, a la inversa, el hogar se proyectaba hacia el espacio público en forma de coladas, órdenes gritadas a los nińos desde las ventanas y disputas aireadas en las aceras. La permeabilidad entre la esfera pública y la privada que tanto impacientaba a los reformistas -y que poco más de un siglo después algunos autores interpretarían como síntoma de vitalidad urbana y cohesión social (Jacobs, 1961) - era el fruto espacial de una reproducción social sustentada parcialmente en la dependencia mutua de los vecinos ${ }^{3}$.

3 Por supuesto esto no significaba que todas las relaciones fueran precisamente amistosas o cordiales. El número de abusos de confianza y allanamientos de morada era directamente proporcional a esta intensidad en las relaciones sociales (Stansell, 1987, p. 56). 
La ciudad y la calle podían constituir un recurso material de forma mucho más literal. Los niños eran habitualmente los encargados de producir esa alquimia mediante un particular "espigueo" urbano, recogiendo en espacios abandonados, entre la basura o robando en los muelles todo tipo de bienes que eran llevados a casa, vendidos a vecinos o reintroducidos informalmente en el mercado. El uso de las calles como un común urbano podía ir aún más lejos, replicando viejos patrones del régimen comunal rural: los cerdos, cabras y otros animales que aún eran frecuentes en la ciudad se encontraban también a sus anchas, alimentándose de los desperdicios que llenaban el espacio público. Sus propietarios lograban con ellos un suplemento informal para la economía doméstica que no puede desestimarse (McNeur, 2011): en 1864, muchos años después de los primeros intentos sistemáticos de erradicar a estos animales de la ciudad, había al menos 20.000 propietarios que aprovechaban las calles para alimentar a sus vacas, cabras y cerdos ${ }^{4}$. El control de las calles era un capital social fundamental que permitía a las clases trabajadoras arreglárselas con poco y asegurar su supervivencia. Pero esa capacidad para apropiarse del espacio público generaba contradicciones que alarmaban cada vez más a la burguesía local. El nuevo cuerpo de policía creado a mediados de la década de 1840 podía recorrer los barrios populares y reprimir las irregularidades más graves; las burbujas socioespaciales de Ladies Mile y la emergente Fifth Avenue podían proporcionar un remedio transitorio para el paseo. Pero estas medidas no eran suficientes. Eran necesarias acciones más ambiciosas, que requerían la intervención de la administración y un desarrollo sustancial de las herramientas de gobierno de la ciudad. Este sería el contexto que daría pie a Central Park.

\section{La producción de nuevos regímenes de espacio público en Central Park}

Hacia mediados de siglo, la expresión material de las contradicciones industriales que hemos seńalado dio nuevo aliento al discurso del Park Movement, que desde hacía varias décadas venía reivindicando la creación de parques públicos en la ciudad $^{5}$. Con todo, la nueva situación en las calles hizo que el programa de la nueva generación de partidarios de las zonas verdes incorporara una orientación menos idealista que la de los pioneros del movimiento, en línea con la evolución del reformismo de la época: el objetivo no era ya, simplemente, crear espacios naturales de reserva para disipar las tensiones inducidas por la sobreestimulación de la ciudad industrial; los parques debían ponerse al servicio de un proyecto gubernamental más amplio que aspiraba a reconfigurar el orden socioespacial de la ciudad con nuevos equipamientos públicos. En este marco podemos comprender hasta qué punto la creación de Central Park fue una respuesta a las prácticas espaciales que poblaban las calles de la ciudad. El parque era un intento de domesticar el caos del espacio público mediante un nuevo régimen de uso que debía suprimir los procesos de apropiación espontánea que hemos descrito, educando a los usuarios en un nuevo patrón de comportamiento monitorizado por la administración. Los promotores de

Artículo en el The New York Times, citado en Goff (2010, p. 108).

Sobre el Park Movement, véase Schuyler (1986, pp. 59-146). 
la iniciativa y, especialmente, Olmsted eran de hecho explícitos al respecto. Central Park debía actuar como un "educador de la población [educator of the people]" (всср, 1862, р. 37). Debido a que "buena parte de los habitantes de Nueva York ignoran lo que es un parque propiamente dicho, (...) deben ser entrenados en el uso adecuado y reprimidos en el abuso del mismo" ${ }^{6}$. Olmsted, que hablaría de los usuarios del parque como el material plástico con el cual construir su obra de arte, recordaría en 1870 que la preservación del orden en el parque "fue desde el principio el mayor reto" y el que "mayor estudio requirió" (Olmsted, 1861; 1971, p. 95). Interesa, desde el punto de vista de la historia del presente que aquí perseguimos, comprender cómo esas innovaciones se incorporaron al propio proceso de diseño y gestión del parque, con el fin de entender cómo se han formado en el pasado técnicas urbanísticas que en algunos casos siguen operativas en la actualidad. La concepción de Central Park fue de hecho uno de los momentos fundacionales de un nuevo régimen de producción del espacio que perseguía la definición y clausura del contenido y sentido del lugar en el propio acto del proyecto, una estrategia que sigue empleándose de forma rutinaria en el diseño urbano contemporáneo. La iniciativa estaba rodeada de una intensa presión por parte de la opinión pública local, en sus distintos estratos de clase, y del propio estado de Nueva York: el volumen de gasto público que acarrearía la ejecución y mantenimiento del parque, la necesaria transformación de la normativa y del propio rol de la administración pública en relación con la propiedad del suelo, la alarma por la posibilidad de que el nuevo equipamiento se convirtiera en un espacio exclusivo para las élites o degradado por las clases populares, todos estos aspectos ejercían una considerable influencia sobre las instituciones responsables. El horizonte más temido, sin duda, era la posibilidad de que un dispositivo pensado para corregir las prácticas espaciales de la ciudad terminara, como el resto de las calles, siendo apropiado por la turba urbana. Ante esa perspectiva, los diseñadores y gestores del parque idearon un sistema que habría de cerrar prematuramente el contenido del espacio público, fijando los usuarios potenciales a los que estaba destinada cada ubicación y asignando a priori formas de uso específicas en una suerte de división, distribución y especialización de las prácticas espaciales posibles en ellos.

La literatura sobre Central Park ha leído la gestación de la iniciativa como un paso más en la evolución del Park Movement. Pero desde el punto de vista de la geografía política implícita en su propuesta y posterior gestión, quizá no sea arriesgado emparentar lejanamente la lógica de esta territorialización desde arriba del espacio público con otros esquemas, mucho menos obvios, activos en experiencias coetáneas en Europa. Los pioneros del Park Movement, en efecto, habían sońado un parque libre, abierto, autorregulado, sin la necesidad de policías. En una visión mucho más sesgada del carácter democrático de los nuevos equipamientos, Olmsted y los Commissioners consideraban que el parque debía "ser protegido del público" (Martin, 2011, p. 166), producir su propio público, crear una nueva forma de aparición en público que supuestamente permitiría el disfrute de todos mediante la prohibición de usos y sujetos "indeseables". La función policial del

Olmsted, citado en Olmsted y Kimball (1973, p. 58). 
parque, entonces, tomaba el primer plano, en términos formalmente opuestos pero politicamente cercanos a las contemporáneas iniciativas de urbanismo policial en Centroeuropa (véase, por ejemplo, Bernet, 2004; Spencer, 1990). La selección de Olmsted, según él mismo confesaría, se debió a que era "uno de los pocos hombres en América que había hecho una profesión del conocimiento en materia de organización y gestión policial" (Olmsted, 1882, p. 23); por encima del diseńo, esta era para él su misión más importante (Rosenzweig \& Blackmar, 1992, p. 122). Se trataba en todo caso de una labor policial amplia, en la que la vigilancia era sólo el último eslabón. Los elementos que la precedían eran de hecho menos obvios, más complejos, innovadores y arriesgados, extendiéndose al conjunto del esquema de gobierno del parque y a las propias tareas de diseño.

Estudiando la transición de los estados policiales a las nuevas formas de gubernamentalidad emergentes en el siglo xix, Michel Foucault (2008, p. 307 y ss.) habló de la Polizeiwissenchaft (ciencia policial) para referirse al conjunto de saberes y técnicas creados para regular la actividad humana. Este régimen policial no operaba sólo mediante la represión -forma moderna de policía-, sino también y sobre todo mediante la "conducta de la conducta", el reparto de actividades y comportamientos que, orquestados por nuevos equipamientos urbanos y configuraciones territoriales, permitirían a la administración anticiparse al conflicto, evitándolo. El modo en que la lógica policial impregnaba la concepción general de Central Park resulta un ejemplo certero de esa innovación gubernamental. El uso de ordenanzas de control del uso, la prohibición de comportamientos impropios y la correspondiente vigilancia y castigo por un cuerpo de policía específico para el parque eran parte del programa para materializar el uso deseado en su interior. Pero se trataba, en realidad, de herramientas de refuerzo, mecanismos de seguridad complementarios a otro mucho menos obvio. El espacio mismo, la red de "lugares" que articulaba el diseño del parque se movilizaba en la aspiración pedagógica del proyecto Greensward antes de recurrir a la normativa y la policía. La propia configuración material de los enclaves especializados del parque debía servir para distribuir y transmitir, velándolo, el intento de influir sobre la actitud de los visitantes. Trasladando la lógica regulatoria al diseño mismo, los promotores pretendían que las bellezas naturales y ordenadas del parque operarían "por la mera elocuencia de sus enseñanzas silenciosas [silent teachings]" como "elementos efectivos para sostener (...) las reglas necesarias para su preservación” (вССР, 1864, p. 29).

Esta exigencia iba a obligar a Olmsted y Vaux a sofisticar sustancialmente su método de trabajo, incorporando una estrategia experimental en la concepción y desarrollo del parque. En 1864, Olmsted especulaba en una carta a Vaux sobre la conexión entre el diseño general y la "administración y gestión del uso que el público hacía del parque", considerando "la relación (...) vaga, pero estrecha; dependiente de la capacidad del diseño para adecuarse a la habituación fácil, conveniente y segura del público a las costumbres que es deseable establecer" (citado en Olmsted \& Kimball, 1973, p. 78). El método adoptado en el diseńo establecía, en primer lugar, un régimen de espacio público estrictamente diferenciado del resto de la ciudad: Olmsted y Vaux consideraban absurda la sugerencia de algunos de que el parque funcionara con la libertad de las calles (Board of Commissioners of 
the Department of Public Parks [BCDPp], 1872, p. 77). A continuación había que diferenciar las distintas áreas del enclave en función de la experiencia deseada, canalizar los flujos de visitantes, separarlos por su modo de desplazamiento o reunirlos a todos para propiciar el espectáculo del encuentro y la mezcla social, reservar ciertos espacios para actividades y grupos estratégicos -especialmente mujeres y niños, que se convertían en sujetos favoritos de los diseñadores- y bloquear el acceso a otros, habilitar magníficas vistas para la contemplación pasiva del paisaje, disponer puntos especiales para actividades conflictivas con el programa del parque -espacios deportivos, lugares para tomar refrescos y bebidas alcohólicas de baja graduación- de forma que fueran fácilmente vigilables, etcétera.

Figura 1 | Plano general de Central Park, en 1870

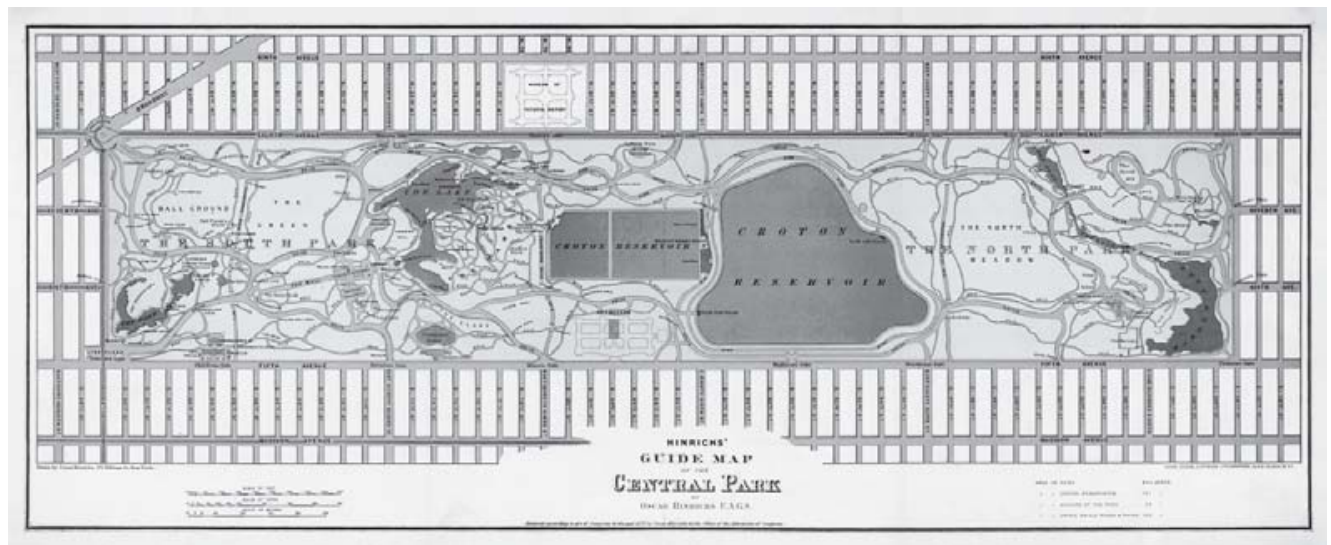

FUENTE HINRICHS (I 875)

Los distintos espacios del parque quedaban pues codificados en el diseño, asociados no sólo a una función, sino también a usuarios concretos, a los usos ideales que éstos debían hacer de dichos espacios y a un conjunto de comportamientos y valores que serían absorbidos por medio de la experiencia propiciada por ellos. A diferencia de algunas de las experiencias que le siguieron en la primera generación de grandes parques públicos en EE.UU. -ideados y representados con frecuencia como enclaves vírgenes, vacíos de usuarios (Gabriel, 2011)-, la administración promovía Central Park con representaciones de espacios habitados, mostrando una prefiguración de los hábitos que se deseaba materializar. La concepción del parque se apoyaba así en buena medida en un ejercicio de place-making, formando una red de lugares especializados, con un significado específico, unidos por espacios de transición sin contenido definido. Como hemos sugerido, los lugares singulares eran espacios cargados ideológicamente, pensados para desempeñar una particular agencia sobre los visitantes. Se unían aquí dos mentalidades dominantes en la época: un régimen histórico de cultura material que establecía una relación causa-efecto entre el medio y el comportamiento social, y una práctica arquitectónica que asignaba significados morales a la forma construida. El resultado era un precedente para formas posteriores de zonificación en el que no sólo las funciones del espacio, sino los propios usuarios y el sentido que éstos debían tener del lugar quedaban clausurados en el 
acto proyectual. Los documentos oficiales, las guías del parque y la prensa se encargarían de popularizar este nuevo sistema de lugares: la Rambla, espacio densamente arbolado y habitualmente representado con parejas jóvenes, que debía convertirse en "el lugar de todos los lugares (...) para los sueños y el ensimismamiento, y que será naturalmente consagrado al sentimiento y al amor" (Richards, 1861, p. 296); el Prado de Ovejas, donde los visitantes podrían relajarse y sentir la influencia beneficiosa del campo sin salir de la ciudad, gracias a una escenificación especialmente concebida para simular un entorno rústico; el Lago, en cuyas representaciones era habitual encontrar personas cantando - presumiblemente obreros- y cuyos cisnes, "excelentes ejemplos de modales y conducta (...) enseñarían lecciones valiosas (...) con sus movimientos dignos y gráciles” (Richards, 1861, p. 298); el Tour y el Camino de Bridas, reservados respectivamente para el paseo de carruajes y los intrépidos jinetes que visitaban el parque -todos ellos de extracción burguesa- para lucir las "últimas modas (...) en un espectáculo brillante e inspirador" (Richards, 1861, p. 296); la Vaquería, ideada inicialmente para las madres jóvenes y sus retońos, sutilmente apartada de la circulación general del parque y diseńada con un aspecto de espacio privado y rural, con vacas, corderos y pollos, destinada a la diversión de los niños pequeños y a dispensar leche, mantequilla y pan a las familias necesitadas; el Paseo y su desembocadura en la Terraza, los espacios más monumentales en los que Vaux logró una elegante combinación de arquitectura y naturaleza, diseńados para acoger a todos los visitantes en los grandes eventos y hacer de la mezcla social un espectáculo democrático en el que el público se exhibía a sí mismo (Conant, 1879, p. 697). La lista de enclaves especializados continuaba: la Pradera de los Nińos, el Estanque de las Damas, la Cabaña de los Chicos, el Parque de Recreo, etcétera.

FIgURA 2 | "Un flirteo [en la] Rambla, donde se concentra el romance de Central Park".

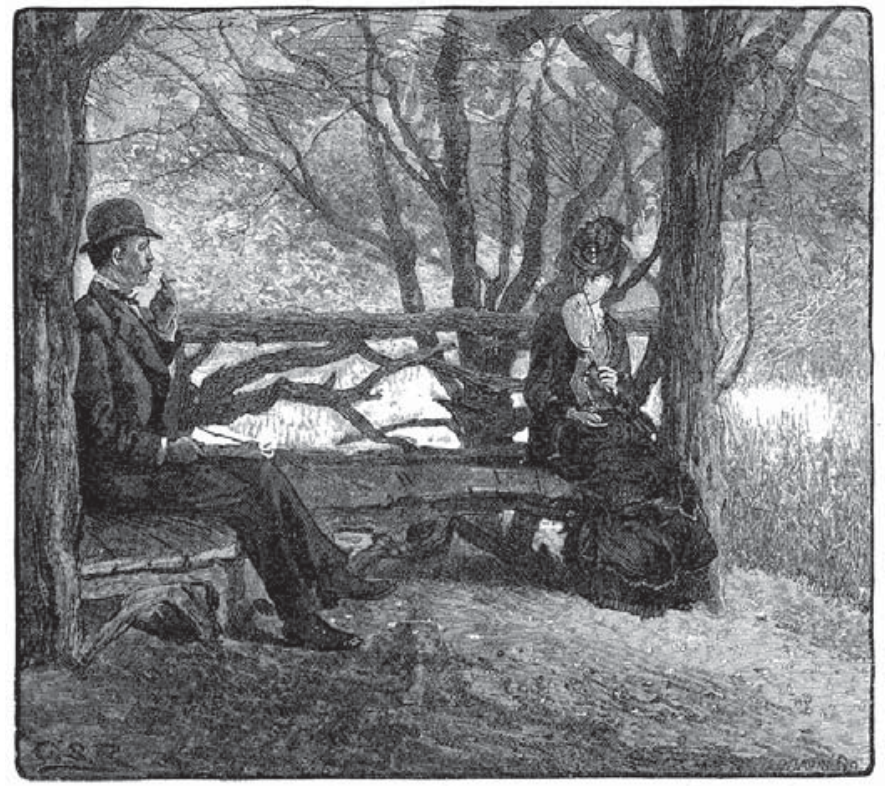

FUENTE CONANT (I 879, PP. 693-694) 
FIgURA 3 | "Los niños se reúnen para alimentar [a los cisnes] con los restos de su picnic".

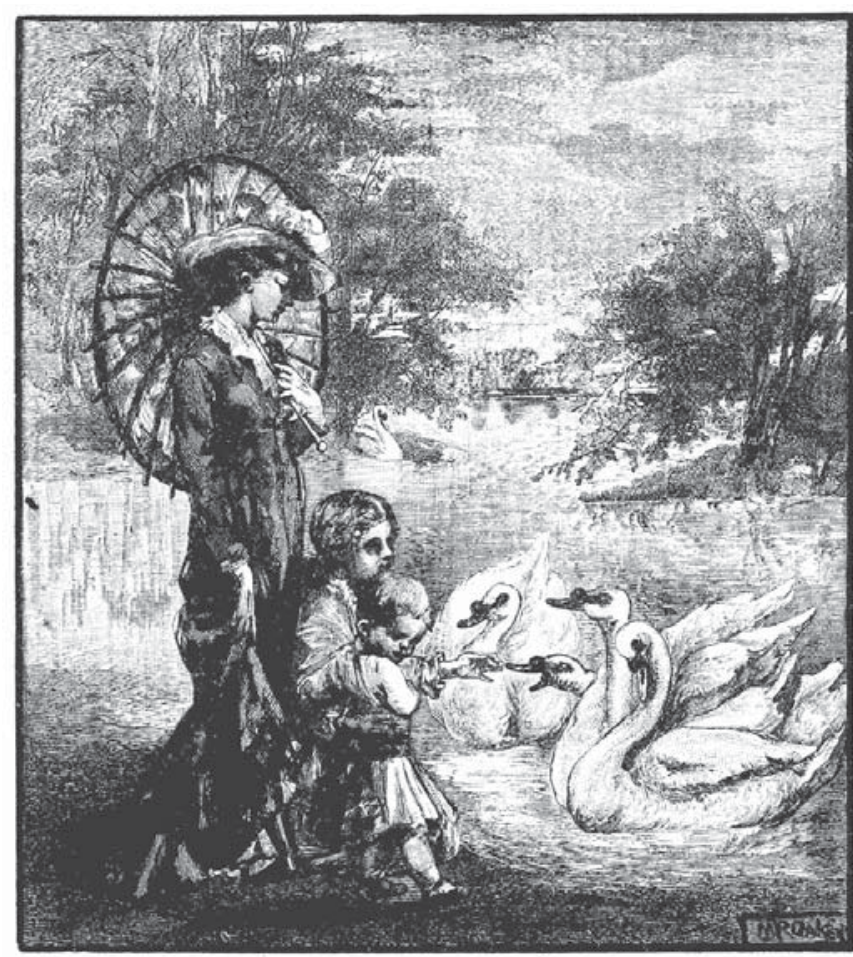

FUENTE CONANT (I 879, P. 696)

Al propio condicionamiento del uso del parque implícito en este método de diseño, representación y difusión, se unían, como hemos indicado, la fijación de unas ordenanzas de uso específicas y la presencia de un cuerpo de policía especialmente entrenado para asegurar su cumplimiento. Las primeras ordenanzas se aprobaron en 1858 , en un intento pionero de regular el uso del espacio público; el objetivo era preservar una experiencia libre de los percances que, a ojos de la élite, arruinaban las calles de la ciudad. La normativa operaba sobre distintos campos, poniendo el mismo acento punitivo sobre aspectos a priori heterogéneos: las formas de acceso y horario de apertura, la presencia de animales ajenos al parque, la preservación de la seguridad, la conservación no sólo de la integridad material del parque -vegetación, arbolado, construcciones, etcétera- sino también de su imagen, el control del cumplimiento de los usos asignados a cada espacio o la corrección del comportamiento, de los gestos y el lenguaje de los visitantes (вССР, 1860, pp. 17-19; 1861, pp. 106109). Se incluían además medidas específicas para impedir la proliferación de rasgos característicos del espacio público convencional: se prohibía explícitamente la venta ambulante y la buhonería, los juegos de azar, la mendicidad, la presencia de músicos callejeros, personas andrajosas, el uso de pancartas, los discursos políticos...

El cuerpo especial de guardas del parque, con una autoridad equivalente a la de la policía local y entrenados con disciplina militar, debía asegurar el cumplimiento de las normas, "precaviendo -advertía Olmsted- a los visitantes para que no las infringieran, (...) interrumpiendo y reprendiendo a los que lo hicieran y, si 
fuera necesario, ... arrestándolos" (citado en Olmsted \& Kimball, 1973, p. 431). A priori los guardas debían actuar como "educadores", "ayudando respetuosamente a los infractores en una mejor comprensión de su deber hacia los demás, como un caballero intentaría guiar a otro" (Olmsted, citado en Burrows \& Wallace, 2000, p. 795). En todo caso, si esto no era suficiente, debían amonestar o detener a los transgresores. El número de arrestos fue reducido a lo largo de la década de 1860, muestra quizá del éxito de los castigos ejemplares impuestos tras la inauguración del parque, con una aplicación especialmente dura de las normas, penas de treinta días de cárcel y multas de 50 dólares, el equivalente a casi cinco meses de un salario medio masculino en la industria textil de la época (Department of Public Parks [DPP], 1870, p. 11; Wilentz, 2004, p. 405).

La trayectoria del proyecto fue más difícil en las décadas siguientes. Olmsted fue paulatinamente apartado de posiciones de responsabilidad, encadenando una serie de dimisiones, reentradas y despidos que ilustraban el difícil equilibrio entre las competencias y agendas del gobierno local y el gobierno del estado de Nueva York, habitualmente opuestos en sus perspectivas sobre el parque. Las normas y vigilancia se relajaron paulatinamente y pronto Olmsted (1882) describiría en su agrio alegato Spoils of the Park cómo las prostitutas y los vagabundos se habían convertido en elementos habituales en ciertos enclaves. Con el número de arrestos aumentando sin cesar, podía decirse que el proyecto implícito en el modelo inicial había fracasado. Incluso si la situación se moderó poco después, parecía claro que este modo de intervención era insuficiente. La ingeniería social perseguida por la reforma urbana de esa época requería un programa más ambicioso, sumando a la política de espacio público acciones en los campos de la vivienda, el trabajo, la educación y el tiempo libre (Boyer, 1992; Plunz, 1990). Las propias estrategias de intervención en el espacio público y la política de parques sufrirían una evolución importante en el último tercio de siglo, dirigida a la expansión del modelo en un intento por hacerlo más efectivo y totalizante. Olmsted desarrolló sus nociones de parkway (vía-parque) y park-system (sistema de parques) con el fin de extender el efecto transformador de los parques a barrios completos y después al conjunto de la ciudad. Durante la Gilded Age y la Progressive Era, los gobiernos locales optaron por la creación de parques de menor tamaño y zonas de recreo (playgrounds) como un modo más eficiente de movilizar la influencia del espacio público reformado allí donde era más necesario: en los barrios obreros (Cranz, 1982; Draper, 1996).

De hecho, era en estos desarrollos posteriores de la reforma urbana donde la influencia de Central Park resultaba más clara. Los resultados a corto plazo del parque sobre el comportamiento de los usuarios eran difíciles de evaluar. Los testimonios coetáneos en los documentos oficiales, la prensa y la literatura se dividen entre la celebración del lugar como un espacio de encuentro y convivencia armónica y la crítica a los abusos y mal comportamiento de ciertos grupos aislados. Pero la ideología de la reforma, entendida como un ejercicio de formación de la conducta que Olmsted y los comisarios del parque habían articulado en el proyecto inicial, fue asumida y amplificada por las experiencias posteriores hasta hacerse hegemónica durante la Progressive Era, entre las décadas de 1890 y 1920. Dicha herencia era especialmente obvia en las nuevas políticas de espacio público desplegadas en 
este período (Boyer, 1992, pp. 233-251). Los parques de barrio y los playgrounds heredarían la misión de Central Park como alternativas a la "influencia nociva de la taberna, la banda callejera y males similares" (Riis, 1903, p. 168), concibiéndose como dispositivos para modelar el "comportamiento colectivo" mediante un "control de los individuos” operado en el espacio público (Rainwater, 1922, pp. 290-293).

\section{Conclusiones: \\ hacia una reconceptualización de la producción del espacio público}

Tanto el debate reciente sobre el espacio público como la investigación más amplia sobre los modos de regulación urbana indican que estas dinámicas están lejos de ser asuntos del pasado. Podemos, sin ir más lejos, rastrear una historia contemporánea de intervenciones espaciales de los procesos de reproducción social en Nueva York a lo largo de la segunda mitad del siglo xx (Chronopoulos, 2011). En el caso de Central Park, el legado ideológico de Olmsted fue tomado explícitamente como un elemento inspirador para el ejercicio de rehabilitación y redisciplinamiento de la década de 1980, tras un período de decadencia alimentado por los recortes posteriores a la crisis fiscal de ańos anteriores (Rosenzweig \& Blackmar, 1992, pp. 510-514). Junto a la privatización parcial de los servicios del parque, el nuevo programa incluyó un régimen mucho más restringido de actividades e intentos de expulsar a los vagabundos y otros sujetos "indeseables", convirtiéndose en un modelo para la intervención en otros parques de la ciudad: Bryant Park (Madden, 2005), Tompkins Square Park (Smith, 1996), Union Square (Zukin, 2010)... Se trata de experiencias que glosan, de un modo u otro, las repercusiones de la polarización y monopolio en la producción y control del significado y contenido del espacio público (Salcedo Hansen, 2002; Viladevall \& Castrillo, 2010): expulsión de las prácticas tradicionales, bloqueo de la apropiación espontánea por parte de los usuarios y su sustitución por simulacros de civismo, imposición de sistemas de vigilancia y seguridad cada vez más exhaustivos para monitorizarlos, mercantilización o privatización del espacio público...

Estas tendencias se presentan como variaciones en el intento de producir un régimen de publicidad controlado institucionalmente, congelando la dialéctica entre la concepción y el uso del espacio que Henri Lefebvre (1991), y más tarde Don Mitchell (1995), identificaron como dinámica subyacente a todo espacio público (véase también Stanek, 2011, pp. 133-158; Stanek \& Schmid, 2011). Sin embargo, el espacio público permanece siempre abierto, de una forma u otra, a la posibilidad de cambio y reapropiación, y en esa apertura sigue implícita una promesa democrática (Dikeç, 2005; Massey, 2012). Buena muestra de ello, las recientes tomas de la calle por movimientos sociales de diversa ascendencia han despertado el interés de cierta filosofía política por la posibilidad de imaginar nuevos "espacios de aparición" colectiva en una línea vagamente arendtiana (Butler, 2011; Žižek, 2012, pp. 78-89).

Pero las recientes ocupaciones de la calle y la reapropiación colectiva del espacio público a través de las grietas de su actual régimen de uso pueden resultar desorientadoras. La historia de Central Park muestra que esa promesa debe ser tomada con cautela y en el largo plazo, y que las posibles reapropiaciones requerirán algo más que una toma temporal de las calles. Entre otras, será necesaria una apuesta decidida 
por parte de planificadores y urbanistas por deconstruir sus prácticas con el fin de depurarlas de toda instancia desposeedora que pueda anidar en ellas. ¿Podemos imaginar, por ejemplo, una concepción del espacio público que prescinda de las estrategias de producción de un usuario normalizado y un público medio, tan obvias en el proyecto de Central Park? Más ampliamente, ¿podemos estar seguros de la neutralidad de nuestras técnicas, de nuestros modelos, herramientas de diseño y gestión de la ciudad? La historia de Central Park muestra que una parte de la función policial y de producción de orden social del proyecto se delegaba en cuerpos de seguridad convencionales; pero otra, mucho más sofisticada, quedaba incorporada a la propia concepción del parque por medio de ordenanzas y, sobre todo y de modo más sutil, al propio proceso de place-making, a la ideación y definición de los lugares que estructuraban y daban sentido al parque. La historia de nuestra disciplina nos ha legado instrumentos cargados de una agencia secundaria (Gell, 1998), por medio de los cuales configuraciones de poder pretéritas intentaron distribuir su ejercicio de dominio y hegemonía social. En otras palabras, las herramientas de diseńo y formación de lugares que manejamos rutinariamente en nuestros planes y proyectos no son inocentes y podrían estar bloqueando las aspiraciones honestas de muchos urbanistas a producir espacios de emancipación social. El caso de Central Park muestra, por ejemplo, que la habitual especialización espacial que empleamos en la estructuración del espacio público de nuestras iniciativas está ligada históricamente a una tipificación de los usuarios y a un intento por suprimir algunos de sus capitales sociales, precisamente aquellos que ponen en peligro, por su potencial de apropiación autónoma, la asignación y clausura del sentido del espacio en el proyecto urbanístico.

Pero ¿`cómo imaginar prácticas de espacio público alternativas? Aunque esa indagación excede los límites de este artículo, se esbozarán algunas líneas de trabajo partiendo de los aspectos identificados en el caso aquí expuesto. El proyecto inicial para el parque intentaba moldear los comportamientos de los usuarios mediante una clausura prematura y pretendidamente finalista de los usos del espacio y el sentido de lugar que éstos contribuían a formar. Las estrategias dirigidas a este fin operaban en distintos planos, desde la concepción de la estructura y enclaves del parque a la gestión del mismo. En consecuencia, un acercamiento al espacio público comprometido con la capacidad de los usuarios para la apropiación espontánea debería trabajar en líneas que refuercen su apertura constitutiva. En ese sentido parecen necesarios: i) otros modos de diseño, en que se evite concebir el espacio público como un espacio de excepción o uso exclusivo, propiciando la interacción con el entorno inmediato o incluso la mezcla con el mismo, con otras dotaciones, espacios libres y actividades; ii) otros modos de uso del espacio, ajeno al disfrute pasivo condicionado por las ordenaciones y ordenanzas y más atento, no tanto a "necesidades" identificadas desde arriba, como a la capacidad de los ciudadanos para desencadenar dinámicas de apropiación de forma autónoma; iii) otros modos de gestión, promoviendo modelos de autogestión y conservación por parte de los colectivos que participen en la vida de estos equipamientos. La capacidad del urbanista para trabajar con estos materiales dependerá en buena medida de su esfuerzo por ampliar las dimensiones del fenómeno urbano consideradas en la práctica 
urbanística convencional. Ésta presenta habitualmente una infinidad de campos ciegos, subanalizados, especialmente en lo que atañe a los procesos que conforman los patrones de vida cotidiana, un aspecto clave para la comprensión del funcionamiento del espacio público. En definitiva, una práctica urbanística emancipadora no sólo debe utilizar de otro modo sus técnicas; al hacerlo, debe prestar atención a otras facetas de lo real e idear útiles nuevos para comprenderlas.

Este artículo ha intentado mostrar la contribución que una revisión crítica de nuestro pasado disciplinar puede tener en estos empeños por reconceptualizar nuestras técnicas. Esta deconstrucción teórica de la disciplina debe articularse a un análisis que nos permita comprender cómo ha llegado a ser posible el sujeto urbano contemporáneo; en otras palabras, debemos producir una genealogía urbana de nuestro presente socioespacial colectivo. En concreto, para el caso del espacio público, los parques y otras zonas verdes, debemos dilucidar si nuestros actuales planteamientos sobre su papel en la estructura urbana y nuestras perspectivas sobre su uso y funcionamiento interno llevan o no la impronta de pasados que pongan en peligro su verdadero potencial de servicio público. Este contexto de reconceptualización puede ser tomado como oportunidad para la revisión del rol de la práctica urbanística y de la propia figura del planificador, desplazando su atención a un plano inmanente, metamorfológico y plenamente inscrito en una perspectiva de equidad social. El urbanista debe aceptar la apertura radical del espacio y asumir las limitaciones -y falta de estatura democrática- de todo intento por clausurar prematuramente el contenido y significado de los lugares que sus proyectos producen. El resto tendrán que construirlo los propios ciudadanos, sustrayendo paulatinamente al espacio abstracto y concebido de la planificación prerrogativas y territorios de acción a medida que la experiencia directa del espacio vivido que les permita vislumbrar una reclamación más amplia y profunda del espacio público.

\section{Referencias bibliográficas}

Beckert, S. (2003). The monied metropolis: New York City and the consolidation of the American bourgeoisie, 1850-1896. Cambridge: Cambridge University Press.

Bellows, H.W. (1861). Cities and parks. With special reference to the New York Central Park. Atlantic Monthly, 7, 416-429.

Bernet, C. (2004). The 'Hobrecht Plan' (1862) and Berlin's urban structure. Urban History, 31(3), 400-419. doi:10.1017/S0963926805002622.

Bernstein, I. (1990). The New York City draft riots. Their significance for American society and politics in the age of the Civil War. Nueva York: Oxford University Press.

Blackmar, E. (1989). Manhattan for rent: 1785-1850. Ithaca: Cornell University Press.

Board of Commissioners of the Central Park (вССР). (1860). Third Annual Report. Nueva York: Bryant \& Co.

Board of Commissioners of the Central Park (вССР). (1861). Fourth Annual Report. Nueva York: Bryant \& Co. 
Board of Commissioners of the Central Park (вССР). (1862). Fifth Annual Report. Nueva York: Bryant \& Co.

Board of Commissioners of the Central Park (вССР). (1864). Seventh Annual Report. Nueva York: Bryant \& Co.

Board of Commissioners of the Department of Public Parks (всDpp). (1872). Second Annual Report. Nueva York: Bryant \& Co.

Bondi, L. \& Domosh, M. (1998). On the contours of public space: A tale of three women. Antipode, 30(3), 270-289. doi: 10.1111/1467-8330.00078

Boyer, M. C. (1985). Manhattan manners. Architecture and style, 1850-1900. Nueva York: Rizzoli.

Boyer, P. S. (1992). Urban masses and moral order in America, 1820-1920. Cambridge, MA: Harvard University Press.

Burrows, E. \& Wallace, M. (2000). Gotham: A history of New York City to 1898. Nueva York: Oxford University Press.

Butler, J. (2011). Bodies in alliance and the politics of the street. Transversal, 10/11 [en línea]. En http://www.eipcp. net/transversal/1011/butler/en.

Chronopoulos, T. (2011). Spatial regulation in New York City: From urban renewal to zero tolerance. Nueva York: Routledge.

Conant, H.S. (1879). A Ramble in Central Park. Harper's New Monthly Magazine, 59, 689-701.

Cranz, G. (1982). The politics of park design: A History of urban parks in America. Cambridge, MA: MIT Press.

De Certeau, M. (1988). The writing of history. Nueva York: Columbia University Press.

Department of Public Parks (DPP) (1870). Laws Respecting the Central Park. Nueva York: The New York Printing Company.

Dikeç M. (2005). Space, politics, and the political. Environment and Planning D: Society and Space, 23(2) 171-188. http://dx.doi.org/10.1068/d364t

Domosh, M. (1998). Those "gorgeous incongruities": Polite politics and public space on the streets of nineteenth-century New York City. Annals of the Association of American Geographers, 88(2), 209-226. doi: 10.1111/1467-8306.00091

Draper, J. (1996). The art and science of park planning in the United States: Chicago's small parks. En M. Corbin Sies \& C. Silver (Eds.), Planning the twentieth-century American city. Baltimore: Johns Hopkins University Press.

Elden, S., Gregory, D. \& Sevilla-Buitrago, A. (2011). Spaces of the past, histories of the present: An interview with Stuart Elden and Derek Gregory. ACME: An International E-Journal for Critical Geographies, 10(2), 313-339. En http://www.acme-journal.org/ vol10/Eldenetal2011.pdf

Foucault, M. (1975). Surveiller et punir. Naissance de la prison. París: Gallimard.

Foucault, M. (2008). Seguridad, territorio, población. Madrid: Akal.

Gabriel, N. (2011). The work that parks do: towards an urban environmentality. Social \& Cultural Geography, 12(2), 123-141. doi: 10.1080/14649365.2011.545139

Gandy, M. (2002). Concrete and clay: Reworking nature in New York City. Cambridge, MA: MIT Press.

Gell, A. (1998). Art and agency: An anthropological theory. Oxford: Clarendon.

Goff, L. (2010). Shantytowns in the United States, 1820-1890. Tesis doctoral, University of Virginia. 
Greene, A. (1837). A glance at New York. Nueva York: Craighead \& Allen.

Hinrichs, O. (1875). Hinrichs' map guide of the Central Park. New York.

Jacobs, J. (1961). The death and life of great American cities. Nueva York: Random House.

Lefebvre, H. (1991). The production of space. Oxford: Blackwell.

Madden, D. (2005). Revisiting the end of public space: Assembling the public in an urban park. City \& Community, 9(2), 187-206. doi: 10.1111/j.1540-6040.2010.01321.x

Martin, J. (2011). Genius of place. The life of Frederick Law Olmsted. Cambridge, MA: Da Capo. Massey, D. (2005). For space. London: Sage.

Massey, D. (2012). Espacio, lugar y política en la coyuntura actual. Urban, nueva serie 4, 7-12. En http://polired.upm.es/index.php/urban/article/view/1864/2117

McNeur, C. (2011). The "Swinish Multitude": Controversies over hogs in antebellum New York. City. Journal of Urban History, 37, 639-660.

Mitchell, D. (1995). The end of public space? People's park, definitions of the public, and democracy. Annals of the Association of American Geographers, 85(1), 108-133. doi: 10.1111/j.1467-8306.1995.tb01797.x

Olmsted, F. L. (1861). Letter to the Board of Commissioners of the Central Park. January $22^{\text {nd }}$.

Olmsted, F. L. (1882). The spoils of the park, pamphlet.

Olmsted, F. L. (1971). Civilizing American cities. A selection of Frederick Law Olmsted's writings on city landscapes. S. B. Button (Ed.). Cambridge, MA: MIT Press.

Olmsted, F. L. Jr. \& Kimball, T. (Eds.) (1973). Forty years of landscape architecture: Central Park. Cambridge, MA.: MIT Press.

Plunz, R. (1990). A history of housing in New York City. Nueva York: Columbia University Press. Rainwater, C. (1922). The play movement in the United States. Chicago: University of Chicago Press.

Rancière, J. (2003). Politics and aesthetics: An interview. Angelaki: Journal of the Theoretical Humanities, 8(2), 194-211. doi: 10.1080/0969725032000162657

Richards, T. A. (1861). Central Park, New York. Harper's New Monthly Magazine, 23, 289-306. Riis, J. (1903). The peril and the preservation of the home. Philadelphia: Jacobs \& Co.

Rosenzweig, R. \& Blackmar, E. (1992). The park and the people. A history of Central Park. Ithaca: Cornell University Press.

Salcedo Hansen, R. (2002). El espacio público en el debate actual: Una reflexión crítica sobre el urbanismo postmoderno. EURE, 28(84), 5-19. http://dx.doi.org/10.4067/S025071612002008400001

Scherzer, K. (1992). The unbounded community. Neighborhood life and social structure in New York City, 1830-1875. Londres: Duke University Press.

Schuyler, D. (1986). The new urban landscape. The redefinition of city form in nineteenth-century America. Baltimore: Johns Hopkins University Press.

Sennett, R. (1992). The fall of public man. Nueva York: WW Norton.

Smith, N. (1996). The new urban frontier: Gentrification and the revanchist city. Nueva York: Routledge.

Sorkin, M. (Ed.). (1992). Variations on a theme park: The new American city and the end of public space. Nueva York: Hill \& Wang.

Spencer, E. G. (1990). Policing popular amusements in German cities: The case of Prussia's Rhine Province, 1815-1914. Journal of Urban History, 16, 366-385.

Stanek, L. (2011). Henri Lefebvre on space. Architecture, urban research, and the production of theory. Minneapolis: University of Minnesota Press. 
Stanek, L. \& Schmid, C. (2011). Teoría, no método: Henri Lefebvre, investigación y diseño urbanos en la actualidad. Urban, nueva serie 2, 59-66. En http://polired.upm.es/ index.php/urban/article/view/1491

Stansell, C. (1982). Women, children, and the uses of the streets: Class and gender conflict in New York City, 1850-1860. Feminist Studies, 8(2), 309-335.

Stansell, C. (1987) City of women. Sex and class in New York 1789-1860. Chicago: University of Illinois Press.

Stein, C. (1957). Towards new towns for America. Nueva York: Reinhold.

Stelzle, C. (1926). A son of the Bowery: The life story of an East Side American. Nueva York: G. H. Doran.

Stott, R. (1990). Workers in the metropolis: Class, ethnicity, and youth in antebellum New York City. Ithaca: Cornell University Press.

Taylor, D. (1999). Central Park as a model for social control: Urban Parks, social class and leisure behavior in nineteenth-century America. Journal of Leisure Research, 31(4), 420-477.

Viladevall, M. \& Castrillo, M. (2010). Espacio público en la ciudad contemporánea. Perspectivas críticas sobre su gestión, su patrimonialización y su proyecto. Valladolid: Instituto Universitario de Urbanística.

Wilentz, S. (1979). Crime, poverty and the streets of New York City: The diary of William H. Bell, 1850-51. History Workshop, 7, 126-131.

Wilentz, S. (2004). Chants democratic. New York City and the rise of the American working class, 1788-1850. Nueva York: Oxford University Press.

Žižek, S. (2012). The year of dreaming dangerously. Nueva York: Verso.

Zukin, S. (2010). Naked city: The death and life of authentic urban places. Oxford: Oxford University Press. 